\title{
Um negócio da China: o discurso do guānxì nas articulações no âmbito organizacional
}

\author{
A business of China: the discourse of guānxì in articulations within the organizational \\ sphere
}

\author{
Osíris Luís da Cunha Fernandes ${ }^{1}$ \\ Nelson da Cruz Monteiro Fernandes ${ }^{2}$ \\ Fernando Gomes de Paiva Júnior ${ }^{3}$ \\ Sérgio Carvalho Benício de Mello ${ }^{4}$
}

\section{Resumo}

Este estudo explora o guānxì como discurso organizacional vigente na cultura de negócios nas organizações chinesas a partir da lógica da equivalência e da lógica da diferença propostas por Ernesto Laclau e Chantal Mouffe. O guānxì consiste em um relacionamento interpessoal e na criação de conhecimento colaborativo que envolve um saber tácito, orientado para o futuro, complexo que opera em contexto específico. Em uma perspectiva pós-estruturalista aplicada às organizações, utilizamos a análise de discurso como método que permite pôr em prática o papel da linguagem na condição de eixo de compreensão de processos sociais, como acontece com o guānxì. Analisamos 3 entrevistas em profundidade realizadas com chief executive officers (CEOs) chineses e 32 reportagens relacionadas à prática do guānxì em organizações do setor terciário, publicadas em 2 dos maiores diários digitais da China. Com isso, nosso

Os autores agradecem à Coordenação de Aperfeiçoamento de Pessoal de Nível Superior (Capes), pelo apoio concedido para a realização deste estudo.

Artigo submetido em 18 de abril de 2013 e aceito para publicação em 07 de outubro de 2013.

\section{DOI: http://dx.doi.org/10.1590/1679-39518218}

Doutorando em Administração no Programa de Pós-graduação em Administração da Universidade Federal de Pernambuco (PROPAD/UFPE); Mestre em Tourism Management pela Beijing International Studies University (BISU, China); Pesquisador do Lócus de Investigação em Economia Criativa do CCSA/UFPE. Endereço: Universidade Federal de Pernambuco. Centro de Ciências Sociais Aplicadas. Departamento de Ciências Administrativas. Av. dos Funcionários, s/n, 1ํandar - sala D-28 - Cidade Universitária, CEP 50740-580, Recife-PE, Brasil. E-mail: osiriscunha@gmail.com

2 Doutor em Administração pela Universidade Federal de Pernambuco (UFPE); Pesquisador do Lócus de Investigação em Economia Criativa do CCSA/UFPE. Endereço: Universidade Federal de Pernambuco. Centro de Ciências Sociais Aplicadas. Departamento de Ciências Administrativas. Av. dos Funcionários, s/n, 1ํandar - sala D-28 - Cidade Universitária, CEP 50740-580, Recife-PE, Brasil. E-mail: cruzfernandes55@gmail.com

3

Professor Associado do Departamento de Ciências Administrativas da Universidade Federal de Pernambuco (DCA/UFPE); Doutor em Administração pela Universidade Federal de Minas Gerais (UFMG); Membro efetivo do Programa de Pós-Graduação em Administração da instituição (PROPAD/UFPE); Pesquisador do Lócus de Investigação em Economia Criativa do CCSA/UFPE. Endereço: Universidade Federal de Pernambuco. Centro de Ciências Sociais Aplicadas. Departamento de Ciências Administrativas. Av. dos Funcionários, s/n, 1ํandar - sala D-28 - Cidade Universitária, CEP 50740-580, Recife-PE, Brasil. E-mail: fernando.paivair@gmail.com

${ }^{4}$ Professor Associado do Departamento de Ciências Administrativas da Universidade Federal de Pernambuco (DCA/UFPE); Ph.D. em Business Studies pela City University London (CITY, Inglaterra); Membro efetivo do Programa de Pós-Graduação em Administração da instituição (PROPAD/UFPE); Pesquisador e coordenador do Lócus de investigação em Economia Criativa do CCSA/UFPE. Endereço: Universidade Federal de Pernambuco. Centro de Ciências Sociais Aplicadas. Departamento de Ciências Administrativas. Av. dos Funcionários, s/n, $1^{\circ}$ andar, Cidade Universitária, CEP 50740-580, Recife-PE, Brasil. E-mail: sergio.benicio@gmail.com 
objetivo foi identificar a forma como esse fenômeno tem sido apropriado como discurso no âmbito organizacional a partir da lógica da equivalência e da lógica da diferença. Constatamos que as organizações chinesas utilizam o guānxì para obterem acesso preferencial a atores estratégicos que têm informações e recursos demandados nos processos negociais, com vista a obterem vantagens competitivas. Por outro lado, o sucesso dos negócios envolvendo essas organizações depende de uma identificação mútua entre seus líderes, baseada na confiança e credibilidade estabelecidas nas articulações.

Palavras-chave: Guānxì. Discurso organizacional. Teoria do discurso. Análise do discurso.

\begin{abstract}
This study explores guānxì as a currently used organizational discourse in the business culture of Chinese organizations through the logic of equivalence and the logic of difference proposed by Ernesto Laclau and Chantal Mouffe. Guānxi consists in an interpersonal relationship and the creation of collaborative knowledge which involves a tacit, future-driven, and complex kind of knowledge operating in a specific context. From a post-structuralist perspective applied to the organizations, we used discourse analysis as a method which allows us to put into practice the role of language as the axis for understanding social processes, as it is the case of guānxì. We analyzed 3 in-depth interviews conducted with Chinese chief executive officers (CEOs) and 32 newspaper reports related to the practice of guānxì in organizations of the tertiary sector, published in 2 of the leading web-based newspapers in China. Thus, we aimed to identify the way how this phenomenon has been appropriated as a discourse within the organizational sphere through the logic of equivalence and the logic difference. We found out that Chinese organizations use guānxì to gain preferential access to strategic actors who have information and resources required in the business processes, in order to obtain competitive advantages. On the other hand, business success involving these organizations depends on a mutual identification between their leaders, based on trust and credibility established in the articulations.
\end{abstract}

Keywords: Guānxì. Organizational discourse. Discourse theory. Discourse analysis.

\title{
Introdução
}

Três décadas após a abertura econômica que pôs fim à era Mao Zedong na China, muitas informações vêm sendo divulgadas acerca do desenvolvimento econômico desse país asiático. Porém, essas informações não têm sido acompanhadas de reflexões sobre as mudanças socioculturais, ideológicas e identitárias (responsáveis por esse desenvolvimento) que acontecem concomitantemente e têm contribuído para a mudança do sentido de ser um empresário chinês na contemporaneidade. Persistem, também, discussões sobre a prática do guānxì no sistema econômico, embora o debate sobre esse tema esteja focado na importância do uso do guānxì em uma economia que caminha em direção a uma suposta racionalidade das ações burocráticas e mercantis (TIAN, 2007).

Estudiosos da cultura chinesa têm enfatizado que as relações comerciais na China combinam laços afetivos e instrumentais. Nesse sentido, teóricos como Yang (1994; 2002), Wang (2007) e Shi, Shi, Chan et al. (2011) defendem que fazer negócios nesse país envolve a criação de um sentimento de obrigação e endividamento rénqíng.

Guānxì (关系 em mandarim), segundo Chung e Hamilton (2001) é um termo sociológico que descreve relacionamentos pessoais que se sustentam na hábil mobilização de imperativos morais em busca de fins difusos e instrumentalmente calculados.

De acordo com Luo (2007), os estudiosos da cultura chinesa concordam que guānxì implica obrigação social e solicitação de favores especiais. Por outro lado, persiste o problema da falta de consenso sobre qual tipo de fenômeno social/organizacional o guānxì representa ou representará no futuro. O guānxì diz respeito ao 
universo dos negócios chineses a exemplo do estilo brasileiro de fazer negócios, que se pauta em atitudes flexíveis e adaptativas, como ilustra o caso do chamado "jeitinho brasileiro". Assim, Motta e Caldas (1997, p. 34) ensinam que "o jeitinho brasileiro é uma prática cordial que implica personalizar relações por meio da descoberta de um time de futebol comum ou de uma cidade natal comum, ou ainda de um interesse comum qualquer". Além disso, Barbosa (1992, p. 32) argumenta que o jeitinho constitui "[...] uma forma 'especial' de resolver algum problema ou situação difícil ou proibida; ou uma solução criativa para alguma emergência, seja sob a forma de burla a alguma regra ou norma preestabelecida, seja sob a forma de conciliação, esperteza ou habilidade". Esse autor esclarece que o jeitinho brasileiro como fenômeno chama atenção devido ao seu caráter universal, multifacetado e ambíguo. Assim, da mesma forma que outras características culturais, ele está presente e influencia as relações de negócios no Brasil. Contudo, isso não significa que toda uma liderança de negócios faça, necessariamente, uso desse expediente cultural.

Estudiosos das organizações chinesas entendem o guānxì como um comportamento estratégico específico que proporciona um conjunto de ferramentas de capital social que facilita o acesso a recursos por meio da troca de obrigações sociais rénqíng (CHEN e CHEN, 2004; 2009).

A relevância de repensar o tema se renova ao lançarmos um olhar a partir da lógica da equivalência e da lógica da diferença que fazem parte do aporte teórico da teoria do discurso de Laclau e Mouffe (2001). Com isso, o corpus desta análise foi constituído por posições assumidas e registradas por meio de entrevistas concedidas por 3 chief executive officers (CEOs) de empresas privadas do setor terciário, localizadas no Distrito Financeiro da capital chinesa, Běijīng, e por 32 reportagens publicadas, em 2010 e 2011, nos 2 maiores diários digitais da China (Xinhuanet e China Daily).

De acordo com o índice DCFI, o Distrito Financeiro da capital chinesa tem se mostrado um dos mais prósperos, ocupando a $6^{\circ}$ posição dentre os centros de negócios mais importantes do mundo e com um potencial de desenvolvimento e crescimento para ocupar as três primeiras posições nos próximos anos, devido ao forte ímpeto de crescimento e estabilidade. Essa peculiaridade enseja um ambiente de negócios altamente competitivo e dinâmico, no qual existem empreendedores de êxito socialmente reconhecidos na atividade empresarial, o que pressupõe a emergência de indícios de uso do guānxì na busca por vantagem competitiva e sustentabilidade e a absorção de recursos necessários ao desenvolvimento de interações com os diversos stakeholders.

Um dos critérios de escolha das organizações corresponde ao fato de praticarem o guānxì em suas relações de negócio. Após uma vivência presencial com essas empresas, foi constatada a prática do guānxì, embora elas não assumam. Diante dessas dificuldades, conseguimos que três empresários se dispusessem a falar sobre o tema, mesmo mantendo relativa discrição sobre essa prática. Os diários têm sua importância por aportar notícias relevantes sobre as atividades de negócio de empresas do setor terciário chinês.

O corpus foi construído tendo em mente o seguinte questionamento: Como o guānxì tem sido apropriado enquanto discurso organizacional por empresas chinesas do setor terciário?

\section{Organizações e Seus Discursos: Um Olhar Sobre o Guānxì}

Nos últimos anos, muitos estudiosos das organizações têm voltado suas atenções para o estudo do discurso organizacional (GRANT, KEENOY e OSWICK, 1998; ALVESSON e KÄRREMAN, 2000a; 2000b; GRANT, HARDY, OSWICK et al., 2004). Esse interesse crescente está relacionado a uma relativa desilusão com muitas teorias e metodologias dominantes, que têm servido de sustentação aos estudos organizacionais, mas não encontram efetividade na forma de fornecer mecanismos de emancipação na órbita sócio-histórica, advindo daí o estímulo para os estudiosos procurarem formas alternativas de descreverem, analisarem e 
teorizarem sobre os processos e as práticas, cada vez mais complexas, que constituem a organização (GRANT, HARDY, OSWICK et al., 2004).

Autores como Phillips e Hardy (2002) e Grant, Hardy, Oswick et al. (2004) afirmam que as organizações são, antes de tudo, constituídas por discursos. Contudo, a variação na maneira como os pesquisadores discorrem sobre e analisam o discurso organizacional pode, em parte, ser atribuída a seus antecedentes teóricos e disciplinares que emanam do mais amplo domínio da teoria e análise do discurso (ALVESSON e KÄRREMAN, 2000a; 2000b; OSWICK, KEENOY e GRANT, 2000; GRANT, HARDY, OSWICK et al., 2004).

Entretanto, Putnam e Fairhurst (2001) lembram que a análise do discurso organizacional cruza diversos campos disciplinares (sociolinguística, análise de conversação, linguística cognitiva, pragmática [incluindo atos de fala, etnografia da fala e análise de interação], semiótica [estudos de retórica e literatura], análise crítica do discurso e estudos pós-modernos), constituindo-se na transdisciplinaridade. Ainda assim, nesse campo de trabalho cada vez mais florescente, os pesquisadores têm afirmado que as organizações são construções discursivas, porque o discurso é o próprio fundamento sobre o qual a vida organizacional é construída (ALVESSON e KÄRREMAN, 2000a; GRANT, HARDY, OSWICK et al., 2004; FAIRHURTS e PUTNAM, 2004).

Os analistas do discurso organizacional também se interessaram pelo construcionismo social (BERGER e LUCKMANN, 2011) e pelos efeitos da linguagem em contextos organizacionais (PHILLIPS e HARDY, 2002). Nesse sentido, Mumby e Clair (1997, p. 181) sugeriram que "organizações só existem na medida em que são criadas pelos seus membros por meio do discurso".

Em linha com a observação de Mumby e Clair (1997), Grant, Hardy, Oswick et al., (2004) mostram como as atitudes cotidianas e o comportamento dos membros de uma organização, juntamente com as percepções do que eles acreditam ser a realidade, são moldadas e influenciadas por práticas discursivas nas quais se engajam e das quais ficam expostos ou sujeitos. Em suma, as práticas discursivas nas organizações "não apenas descrevem coisas, elas fazem as coisas" (GRANT, HARDY, OSWICK et al., 2004, p. xx).

Segundo Luo (2007), o guānxì começou a ser incorporado no discurso organizacional quando os funcionários das empresas que operam na China começaram a perceber que poderiam obter recompensas (comissões ou bônus) ou ser promovidos caso utilizassem seu guānxì pessoal para ajudar suas empresas a atingir seus objetivos. Essa tendência se tornou mais evidente a partir de 1985, quando o número de empresas privadas em distritos e vilas começou a aumentar e empresas estatais começaram a utilizar em sua gestão a "alavanca de responsabilidade contratual" e sistemas de recompensas.

\section{Entendendo o guānxì}

Guānxì (矢系, pronunciado gwan-shee) é geralmente traduzido como relacionamento ou conexões; trata-se de uma palavra chinesa que consiste em dois caracteres: o primeiro, guān, 矢, que significa literalmente portão (um passe ou barreira), e o segundo, xì, 系, que significa ligar (LUO, 2007; YUMEI, 2009).

Na perspectiva de Yeung e Tung (1996), guānxì se refere à construção de um laço entre dois indivíduos que podem trocar interesses e benefícios mútuos por transações pessoais ou sociais, de modo a garantir a manutenção de um relacionamento pessoal. Portanto, o termo é entendido como uma espécie de ponte (entre duas partes, ou mais, envolvidas em negócios) que liga firmemente uma pessoa a outra, com o intuito de alcançar dado objetivo por meio da troca recíproca de favores. No entanto, Park e Luo (2001) lembram que apesar de essa relação ocorrer em nível pessoal, pode ser transformada em ativos 
organizacionais, quando os relacionamentos pessoais servem e são utilizados para o alcance de objetivos das organizações.

Em termos gerais, a prática do guānxì "implica a formação de conexões pessoais diádicas, que pressupõem uma ética de obrigações. Segue o princípio da economia da dádiva (dar, receber e retribuir), com vistas à formação de redes sociais, guānxìwang" (PINHEIRO-MACHADO, 2011, p. 104-105).

Embora exista muita discussão em torno do conceito, ultimamente, pesquisadores têm defendido que guānxì nada mais é do que uma forma chinesa ou "um brilho orientalista para rede social", e que "há uma tendência de ver, nos fenômenos chineses, mais do que eles realmente são" (PINHEIRO-MACHADO, 2011, p. 104105). De todo modo, vale frisar que fora da China (continental), especialmente nas regiões de Hong Kong e Taiwan, entre as comunidades das minorias étnicas chinesas no sudeste asiático e em outros lugares, guānxì tem, supostamente, uma função crítica, que é unir a diáspora chinesa pelo mundo.

Verhezen (2008) aponta que guānxì tem conotações positivas e negativas, sendo que as negativas dominam a maioria das discussões, com alguns críticos a defenderem que sua prática contribui para o aumento da corrupção na China, onde o social é formado por uma infinidade de identidades que ganham corpo por meio de relações discursivas antagônicas e, por isso, esse fenômeno constitui um obstáculo à criação de uma sociedade moderna baseada no Estado de Direito. Entretanto, para os que têm um olhar mais favorável, guānxì acrescenta um elemento de humanidade às operações (principalmente as ligadas a negócios), por vezes frias, ajudando, sobretudo em situações de ausência de regulamentação consistente ou diretrizes para a conduta social (FERNANDEZ, 2004).

Em nações socialistas, como a China, o estabelecimento de operações corporativas em uma base neoclássica capitalista tem colocado obstáculos e desafios que precisam ser abordados para que se possa maximizar o valor das corporações. Verhezen (2008) assegura que isso é evidente, por exemplo, no Vietnã e na China, mas, também, na Indonésia e na Tailândia, países que ainda enfrentam grandes desafios socioeconômicos, e todos contaminados por altos níveis de corrupção. Esse mesmo autor lembra que na Indonésia e na Malásia um número considerável de empresários estrangeiros (mormente chineses) e locais utilizam a estratégia de construção de laços sociais com pessoas que podem facilitar, de alguma forma, seus investimentos ou ajudar a garantir contratos favoráveis. Essa estratégia de laços sociais se baseia, principalmente, em garantias sociais e relacionamentos que podem acelerar drasticamente e aumentar as possibilidades de se conseguir um contrato, geralmente à custa das garantias legais (VERHEZEN, 2003; 2008).

Dar presentes, como forma de estabelecer alianças, laços e redes, é uma prática comum na maioria das culturas tradicionais (CHUA, MORRIS e INGRAM, 2009). Igualmente, a busca por uma posição vantajosa em relacionamentos e redes sociais tem sido uma forma predominante de os asiáticos sobreviverem em suas comunidades, além de procurarem ganhar uma vantagem competitiva nos negócios, como indica Verhezen (2002).

Guānxì pressupõe a criação de obrigações para trocas contínuas baseadas na confiança e credibilidade estabelecidas entre duas ou mais pessoas (DUNFEE e WARREN, 2001). Desse modo, o ato de dar presentes pode ser interpretado como o cumprimento de regras de reciprocidade não escritas, percebidas como uma expressão de reconhecimento pela participação em uma rede de relações pessoais, guānxìwang. Como expressões de reconhecimento e gratidão, presentes refletem uma forma de contrato social dinâmico. Geralmente, expressam o respeito pela outra pessoa. Tais práticas estão ligadas por rituais públicos específicos ou formas de cortesia e pelas regras de legitimidade moral que fortalecem os relacionamentos. Portanto, embora a troca de presentes reflita a riqueza relativa das partes envolvidas, essa prática constitui uma maneira de cultivar relacionamentos e de fortalecer o compromisso, a confiança e a reciprocidade. 
Assim, em uma situação na qual há uma desconfiança generalizada do sistema jurídico e político, como ocorre na China, a criação e consolidação de conexões e interações sociais por meio do guānxì proporciona uma forma de confiança alternativa que ajuda na melhoria da rentabilidade dos investimentos e redução de interferências burocráticas arbitrárias (da máquina estatal) que não sejam do interesse dos investidores (CHEE e WEST, 2004; TIAN, 2007; LUO, 2007). Certamente, esse sistema possui inúmeros paralelos com práticas presentes em todas as sociedades, constituindo, portanto, mais um exemplo de economia da dádiva (YAN, 1996; YANG, 1994; 2002), de rede social e de "laços fortes" (GUTHRIE, 2002), de capital social (SMART, 1993), de clientelismo (GOLD, 1985) e até do "jeitinho brasileiro" (PINHEIRO-MACHADO, 2011). Todavia, por alimentar um rico campo semântico, por sua valorização altamente consciente, por se estender a diversas áreas da vida social e, finalmente, por manter uma ética afetiva e moral bastante complexas, o guānxì extrapola todos esses conceitos mencionados.

O guānxì manifesta-se em diversos contextos, na vida rural e urbana, na sociedade capitalista e na comunista - metamorfoseando-se, mas mantendo uma matriz de significado. Seguindo as regras da reciprocidade, sua prática deixa as pessoas em débito por meio de negociações, em regra, entre duas pessoas de hierarquias diferentes. Significa que estamos diante de uma forma de relacionamento muito particular e estrita, baseada em tratos de lealdade, moralidade, confiança, ajuda mútua e hierarquia. Esses tratos ocorrem por meio de códigos de honra não escritos que têm por objetivo a busca da harmonia, do equilíbrio e da ordem. Isso implica a necessidade de um tempo de construção e cultivo das relações. Por isso, a reciprocidade (bao) ocorre por meio de uma etiqueta e de um ritual (li) contínuo e o descumprimento do sistema de obrigações faz com que o receptor em débito perca prestígio (mianzi) (GOLD, 1985; YANG, 1994; 2002; YAN, 1996; CHAN, 2000; GOLD, GUTHRIE e WANK, 2004).

Considerando os pressupostos teóricos e epistemológicos da teoria do discurso de Laclau e Mouffe (1985; 2001), o ato de estabelecer uma relação hegemônica significa a tentativa de incorporar o maior número possível de elementos sociais no processo de articulação discursiva. O discurso hegemônico do guānxi é um discurso sistematizador e aglutinador que se constitui a partir da criação de um denominador comum entre as demandas dos interagentes. É nesse ponto que as equivalências são produzidas.

O guānxì mistura as dimensões instrumentais e sentimentais, dádiva e mercadoria, sendo baseado em uma ética afetiva forte. Assim como há um retorno pragmático esperado, advindo das relações de trocas, trata-se de um sistema baseado em emoções, as quais variam entre rénqíng (人情), sentimento, e gănqíng (感情), afeição ou emoção. Além disso, para que o relacionamento aconteça, é imprescindível a existência de uma base de interação (guānxìwang), que é uma identificação comum ou um passado compartilhado, ou seja, uma cadeia de equivalência, segundo Laclau e Mouffe $(1985 ; 2001)$. A união de pessoas ao longo da vida é uma questão de destino (缘分, yuánfèn). As bases são diversas, mas há uma ênfase sobre a filiação regional e étnica muito forte. As principais são a família (家庭, jiā), o parentesco (亲戚, qīn $q \bar{\imath}$ ) e todas as suas formas estendidas; o local de origem/raiz/dialeto/comunidade/vizinhança (同乡, tóng xiāng); o local de trabalho (單 位, dān wèi), os colegas de escola (同学, tóng xué); os colegas de associações, negócios etc. (同事, tóng shì), e a relação professor-aluno (老师, lăo shī / 学生, xué shēng). Diante da inexistência de uma base comum, as pessoas se esforçam para se inserirem nas cadeias articulatórias hegemônicas na busca de criar vínculos com grupos dominantes na China a fim de realizarem negócios (JACOBS, 1979; GOLD, 1985; HWANG, 1987; SMART, 1993; YAN, 1996; BURITY, 1997; KIPNIS, 1996; 1997; YANG, 1994; 2002; WANK, 1996; GOLD, GUTHRIE e WANK, 2004).

No âmbito dos negócios, tanto em espaços urbanos como nos rurais, guānxì passou a ser visto como uma forma cínica de relacionamento que detém um poder invisível, e procura obter ganhos "pela porta dos fundos", colocando-se como uma alternativa à falta de base legal, ou às instituições econômicas "fracas". Atualmente, segundo Yang $(1994 ; 2002)$ os banquetes continuam sendo acionados como a mais nobre dádiva, sendo uma forma de comoditização do guānxì. Quando planejados para estabelecer conexões, esses banquetes envolvem um nível maior de rituais e etiquetas do que comumente se exige. Nesses casos, não são 
eventos meramente sociais, pois, em geral, envolvem trocas econômicas e políticas. A seguir apresentamos brevemente - o guānxì se revelando como um discurso organizacional, tendo em vista que é uma prática discursiva na qual muitas organizações chinesas se engajam.

\section{Guānxì se revelando como um discurso organizacional}

A teoria do discurso de Ernesto Laclau e Chantal Mouffe se fundamenta na ideia de que o social deve ser entendido a partir da lógica do discurso. Assim, discurso não deve ser entendido apenas como um simples reflexo de textos, mas como uma "totalidade estruturada resultante da prática articulatória" (LACLAU e MOUFFE, 2001, p. 105). É, ao mesmo tempo, "uma forma de comunicação e um sistema de regras em que sentidos são produzidos", segundo Pereira (2011, p. 24). Mendonça (2009, p. 155) afirma que é, também, uma "categoria que une palavras e ações, que tem natureza material e não mental e/ou ideal".

Discurso é prática - daí a ideia de prática discursiva - uma vez que "quaisquer ações empreendidas por sujeitos, identidades, grupos sociais são ações significativas" (MENDONÇA, 2009, p. 155). Burity (2008, p. 42) segue a mesma linha de raciocínio ao afirmar que discurso é uma "categoria teórica que permite investigar os mecanismos pelos quais os sentidos são produzidos e como eles conferem orientação aos fenômenos sociais". Essa orientação não é, entretanto, pré-determinada, mas produzida e transformada na própria dinâmica discursiva. Mendonça (2009, p. 155) esclarece, ainda, que o social deve ser visto como "um social significativo, hermenêutico", pois ele não "aparece como algo a ser simplesmente desvendado, desvelado, mas compreendido como um campo de lutas construído a partir de sua miríade de formas e várias possibilidades de se alcançar múltiplas verdades, note-se, sempre contingentes e precárias" (MENDONÇA, 2009, p. 155).

O guānxì é uma prática discursiva resultante de articulações que constituem e organizam as relações sociais (e comerciais) na China. Naturalmente que a fixação de sentidos em relação à prática discursiva do guānxì é parcial, a considerar as constantes disputas na relação com discursos concorrentes no contexto organizacional (que são os espaços discursivos).

Considerando as formulações de Laclau e Mouffe (2001, p. xi), entende-se que não há como sentidos sociais serem constituídos previamente, ou se considerar identidades ou movimentos sociais totalmente constituídos com projetos políticos existentes "desde sempre", em direção a um objetivo preciso (teleológico).

Portanto, fica claro que a teoria do discurso privilegia o dinamismo que as sociedades e os diferentes grupos sociais apresentam, construindo-se e desconstruindo-se em arranjos múltiplos que produzem significados, instáveis e, por vezes, hegemônicos, justificando, assim, sua adoção como lente teórica neste estudo.

Neste ponto, vale fazer algumas considerações sobre as duas lógicas da construção do discurso que inspiraram as análises deste estudo e fazem parte do aporte teórico desenvolvido por Lacau: a lógica da diferença e a lógica da equivalência. A lógica da diferença trata as diferenças positivas que existem entre os distintos elementos sociais, portanto, diz respeito à complexidade do social. Um meio de unificar esses elementos é a elaboração de uma estratégia hegemônica que busca incorporar o maior número possível desses elementos sociais por meio de práticas articulatórias. Sob essa lógica, a forma mais provável de unificar esses elementos é a partir da criação das cadeias equivalenciais (PESSOA, 2008). Essas duas lógicas andam juntas e, como tal, são constitutivas de um mesmo processo: a lógica da equivalência existe apenas a partir de um efeito discursivo, decorrente da lógica da diferença.

No contexto das organizações chinesas, o discurso do guānxì não passa da articulação precária e contingente de sentidos em uma cadeia de equivalências, uma vez que ele não se apresenta como "acabado ou objetivamente coerente" (MENDONÇA, 2003b, p. 143). A articulação é o processo que une várias demandas 
sociais como parte de uma estratégia política sistemática. Para Pessoa (2008), na articulação hegemônica, os elementos sociais se unem e compartilham os mesmos objetivos políticos negativos em relação a "outro" discurso. $\mathrm{O}$ que difere das simples alianças em que cada ator mantém sua identidade intacta, uma vez que o que ocorre é uma justaposição de interesses sem a formação de uma base identitária comum. Nesse sentido, a articulação do discurso organizacional do guānxì é o processo que conduz à formação de uma identidade política particular.

A construção dessa identidade é o resultado da ação de agentes estratégicos (individuais ou coletivos) que se esforçam para construir uma identidade completa e fechada, de modo a secundar as diferenças e ameaças que podem desestabilizar o discurso organizacional do guānxì. Nesse sentido, a identidade é baseada no antagonismo social, na identidade de outros e, como tal, estes sempre estarão em perigo de sofrer deslocamentos que podem fazer sucumbir os elementos identitários dominantes. Sob essa lógica, constituemse sujeitos divididos, uma vez que nunca conseguem estabilizar uma identidade completa, pois não param de receber novas demandas. Assim, não conseguem forjar uma identidade estrutural completa nem têm uma completa falta de identidade.

Sob essa lógica, o que acaba se construindo são formações discursivas nas quais se começa a encontrar certas regularidades enunciativas e "regras de formação" em uma dispersão de discursos, ou seja, regularidades de elementos que não estão ligados por nenhum princípio de unidade a priori. Em Foucault (1997), as regras que determinam uma formação discursiva apresentam-se, pois, como um sistema de relações entre objetos, tipos enunciativos, conceitos e estratégias.

\section{Caminhos do Repertório Metodológico}

Este estudo tem caráter qualitativo e, para a compreensão da questão em estudo, adotamos a abordagem da análise do discurso, "um método que visa não só apreender como a mensagem é transmitida, como também explorar o seu sentido" (VERGARA, 2010, p. 18). Sob essa ótica, entendemos que as posições assumidas pelos indivíduos são construídas em suas práticas discursivas, da mesma forma que os objetos, as subjetividades, as atitudes e os preconceitos são constituídos pelo discurso.

O corpus de análise foi composto por 32 reportagens (R) sobre o uso do guānxì com depoimentos de funcionários públicos (FP) e pequenos empresários (PE), publicadas on-line em 2010 e 2011, pela agência de notícias Xìnhuá e pelo jornal China Daily, e por 3 entrevistas em profundidade realizadas com CEOs chineses de empresas privadas do setor terciário (de uma empresa de exportação [identificado nas análises como E1], de um hotel de luxo de 5 estrelas [identificado nas análises como E2] e de uma empresa de marketing e eventos [identificado nas análises como E3]) localizadas no Distrito Comercial Central de Běijīng (Běijīng CBD), o mais importante da capital chinesa (MILLER; VANDOME e MCBREWSTER, $2010)^{5}$.

As entrevistas foram realizadas com base em um roteiro de questões, cujo principal objetivo era servir de ponto de partida para o aprofundamento teórico-empírico, sendo que os atores que participaram da pesquisa foram intencionalmente selecionados, considerando que "a ideia que está por trás da pesquisa qualitativa é a seleção intencional dos participantes ou dos locais (ou dos documentos ou do material visual) que melhor ajudarão o pesquisador a entender o problema e a questão de pesquisa” (CRESWELL, 2010, p. 212).

\footnotetext{
5 Durante a análise dos dados, as reportagens foram identificadas sob a forma de RFP1, 1-10, ou, RPE1, 1-10, por exemplo, e as entrevistas sob a forma de E1, 1-10, por exemplo, em que os números seguintes às letras correspondiam à numeração atribuída a cada reportagem $(R)$ ou entrevista $(E)$, seguidas do indicativo das linhas da página onde o recorte utilizado foi retirado (1-10). As letras FP ou PE depois de $\mathrm{R}$ indicam que a reportagem se refere a um funcionário público ou pequeno empresário respectivamente.
} 
As entrevistas foram conduzidas em inglês e chinês (mandarim) por um dos autores do estudo e depois traduzidas para o português. Ele residiu na China, onde estudou a cultura e a língua chinesas por 3 anos, fatores que contribuem para a validação dos dados.

A análise temática se deu em três momentos: no primeiro, procedemos à organização e preparação dos dados para a análise e a seleção dos procedimentos que iriamos utilizar; em um segundo momento, realizamos uma leitura exaustiva do material coletado, para obtermos uma percepção geral das informações e refletir sobre seu significado global por meio dos procedimentos selecionados no momento anterior; e, em um terceiro momento, procedemos à interpretação dos dados, tendo em vista a produção de inferências e interpretações.

As inferências e interpretações propostas encontram suporte no referencial teórico que norteia o estudo, nesse caso, na teoria do discurso de Laclau e Mouffe (2001), utilizando os conceitos de discurso, lógica da equivalência e lógica da diferença. $\mathrm{O}$ Quadro 1 resume as etapas da pesquisa.

Quadro 1

Etapas da pesquisa

\begin{tabular}{|c|l|}
\hline Passos & \multicolumn{1}{c|}{ Procedimentos metodológicos } \\
\hline $\mathbf{1}$ & Estudo teórico para mapeamento temático \\
\hline $\mathbf{2}$ & Seleção dos atores que faziam parte do campo discursivo em estudo \\
\hline $\mathbf{3}$ & $\begin{array}{l}\text { Realização das entrevistas com base em um roteiro de questões para o aprofundamento } \\
\text { teórico-empírico }\end{array}$ \\
\hline $\mathbf{4}$ & $\begin{array}{l}\text { Leitura exaustiva do material coletado para uma percepção geral das informações e reflexão } \\
\text { acerca de seu significado global }\end{array}$ \\
\hline $\mathbf{6}$ & $\begin{array}{l}\text { Averiguação das equivalências e diferenças na constituição do guānxì como discurso } \\
\text { organizacional }\end{array}$ \\
\hline
\end{tabular}

Fonte: Elaborado pelos autores (2013).

A fase de tratamento dos resultados foi perpassada por idas e vindas interpretativas com apoio dialógico do auditor da investigação (MERRIAM, 1998). O papel do auditor foi exercido por nosso orientador e consistiu em auxiliar no desenho estrutural do artigo. Contamos com suas experiências no delineamento dos procedimentos de coleta, análise e interpretação dos dados da pesquisa, com o intuito de preservar o processo analítico da emergência de vieses interpretativos que poderiam ser realizados imprudentemente pelo pesquisador. Esse processo recursivo possibilitou consubstanciar a análise dos dados por meio dessas atividades de validação.

A reflexividade constitui uma forma de atenuar elementos limitantes que restringem a qualidade das entrevistas e análises de campo. Assim, lembramos a orientação de Creswell (2010) de que a reflexividade é um critério de confiabilidade e diz respeito ao antes e ao depois do acontecimento, gerando transformação no pesquisador, uma vez que este vai se tornando uma pessoa diferente por considerar as inconsistências do estudo ao longo do processo permanente de realização. Desse modo, percebemos que o sujeito, historicamente fazedor da ação empreendedora, contribui para significar 
nosso universo pesquisado, exigindo uma constante reflexão e reestruturação do nosso processo de questionamento, inclusive para reduzir vieses interpretativos.

\section{Análise dos Resultados}

Nesta seção, apresentamos reflexões sobre guānxì enquanto discurso organizacional. As duas lógicas importantes na construção do discurso do guānxì são a lógica da equivalência e a lógica da diferença. Essas duas lógicas possibilitam ao analista explanar o discurso do guānxì que faz parte da cultura chinesa, que se impõe por meio de lutas hegemônicas. Para aclarar esse processo analítico, este tópico será dividido em 3 seções. Na primeira seção discorremos sobre a lógica da equivalência, na segunda sobre a lógica da diferença e na terceira tratamos das equivalências e diferenças na constituição do guānxì.

\section{Lógica da equivalência}

Partindo da perspectiva de Laclau e Mouffe (1985), toda identidade se constitui em uma inter-relação constante com um exterior constitutivo, o qual, ao mesmo tempo que nega essa identidade, constitui sua condição de possibilidade. Sob essa ótica, nenhuma estrutura de significado contém o princípio de seu próprio fechamento, pressupondo, portanto, a existência de uma dimensão que atua de fora dessa estrutura, ou seja, um exterior constitutivo. Esse exterior representa uma dimensão intrínseca a toda relação antagônica, podendo ser entendida, também, como relação impossível entre dois termos, em que cada um deles busca impedir o outro de atingir sua identidade plena (MENDONÇA e RODRIGUES, 2008). Dessa forma, quando um exterior constitutivo fecha, momentaneamente, determinada formação discursiva e cria uma cadeia de equivalências entre seus elementos diferenciais, que passam a se articular de forma não diferencial, é criada uma lógica da equivalência (LACLAU e MOUFFE, 2001). No caso da China, isso pode ser verificado nas relações entre o governo e grupos empresariais, que são as novas elites do país, quando, por meio das conexões interpessoais de ajuda mútua, são construídas articulações equivalenciais sui generis em torno de obrigações sociais e favores especiais, visando ao desenvolvimento de negócios nas mais diversas esferas econômicas, locais e globais.

Desse modo, como "todas as relações de negócios envolvem o governo. Guānxì é apenas o primeiro passo na gestão de relacionamentos com o governo [...]" (R6, 98-100) e seu uso é, também, "[...] comum nos círculos empresariais. De fato, esta prática estendeu-se a quase todos os aspectos da vida em milhares de anos" (R10, 12-14). Sobre esse aspecto, 2 entrevistados afirmaram:

O guānxì, decerto, permitelfacilita contatos de negócios. No Oriente, é praticado extensivamente como forma de aproximação entre pessoas e os resultados são mais do que evidentes, basta olhar para o sucesso de empresários asiáticos à volta do globo. É certo que o mesmo pode ser visto na prática como forma de tentar fugir das leis, entretanto, na sua essência, enfatiza a interação e influência mútua entre as pessoas, a sociedade, as coisas e o próprio universo, potencializando a fluidez da comunicação, com efeitos positivos na eficiência/eficácia, nas ações/decisões nos mais diversos campos. (E1, 12-16)

Eu penso que, agora, as pessoas seguem um pouco mais as regras. Mas, você sabe que mais? Acho que a maioria dos gerentes concorda que, às vezes, é muito mais eficiente e rápido usar o seu guānxì pessoal para resolverem assuntos das suas empresas. [...] eu penso que ter certeza que você conhece as pessoas certas nos lugares certos para que você possa se beneficiar e conseguir fazer negócios é normal e muito importante. (E2, 15-20) 
Diante de um cenário como esse, um discurso que constrói o sujeito (chinês) da igualdade, portador, por exemplo, do direito de igualdade de tratamento, tem de encarar uma subjetivação na ordem do aproveitamento do guānxì, uma vez que na China, "[...] se você aceitar um serviço gratuito de um chinês, você fica moralmente devendo a ele. É um cheque em branco que você coloca na sua mão" (R1, 28-29).

Contrariando os argumentos e as conclusões anteriores de Yang (1994; 2002), Wang (2007) e Shi, Shi, Chan et al. (2011), que afirmam não ser de capital importância a criação de um sentimento de obrigação e de mostrar empatia nas relações comerciais (rénqíng) para conseguir obter vantagens nos negócios, observamos que, dentro do campo de discursividade do guānxì, a prática do rénqíng é primordial, tendo em apreço que o guānxì é um critério importante para as pequenas e médias empresas (PME) ganharem vantagens. Neste sentido, "[...] jantares oferecem um fórum para a construção de relações, especialmente com os bancos [...]" (R8, 15-16).

Além disso, tais "relações sociais e de negócios podem acontecer com os executivos de outras empresas, funcionários dos bancos ou do governo. Essas relações com grupos seletos permitem às empresas obter acesso preferencial a uma série de informações e recursos escassos, incluindo o financeiro" (R8, 21-23). Esse resultado corrobora a tese de Park e Luo (2001) de que guānxì pode ser transformado em ativos organizacionais, quando os relacionamentos pessoais servem e são utilizados para 0 alcance dos objetivos interorganizacionais.

Não obstante todos os discursos sejam permeados pelo poder de forma soft, à medida que "pretendem impor verdades a respeito de um tema específico ou de uma área da ciência, da moral, da ética, etc." (PINTO, 2006, p. 92), entendemos que o discurso do guānxì se destaca de outros nesse particular, porque a luta pelo poder entre a elite chinesa é, de certa forma, explícita. O excerto a seguir esclarece esse aspecto: "Estes exfuncionários, que ainda exercem enorme influência e que são especialistas em manobras do guānxì no governo, são ativos valiosos para as empresas, agindo como um agente entre o governo e as empresas, e negociando dinheiro por poder. É por isso que há demanda por funcionários do governo que foram demitidos ou se aposentaram" (R3, 19-23).

Verificou-se que os gerentes evitam produzir diferenças e procuram criar uma relação equivalencial (de forma instrumental) com pessoas de outras organizações que estão em posições hierárquicas superiores, e, assim, conseguirem benefícios econômicos, ou outros para suas organizações. Os entrevistados explicaram que:

É bom para a nosso hotel se criarmos relações com pessoas que estão em posições hierárquicas superiores nas empresas, ou mesmo com um grupo de organizações poderosas em toda a China que precisam de nossos serviços. [...] Se eu pensar sobre isso estrategicamente, e será melhor para mim e para o hotel ter amigos que são poderosos e competitivos e que podem nos ajudar a alavancar nosso negócio. (E2, 35-40)

[...] é muito difícil fazer a gestão das relações comerciais na China, o que acaba dificultando a descoberta de fornecedores e clientes. Também é difícil encontrar capital aqui. [...] Por enquanto, porém, eu tenho que admitir que eu procuro pessoas do meu grupo de relacionamentos que estão em uma posição mais privilegiada para me ajudar com informações que facilitem a descoberta de clientes e fornecedores. (E3, 29-35)

Todavia, as pessoas da cultura ocidental não aceitam o guānxì como um discurso universal. Essa questão é complexa, porque, ao admitir a não universalidade e a não essencialidade do guānxì, e que este seja identificado como uma "cultura" criada pelos chineses, deparamo-nos com a seguinte questão: como criar essas relações de equivalência e como fazer com que tenha sentido para culturas diversas, sem desconsiderar as diferenças? Um exemplo disso é o discurso de proteção dos trabalhadores migrantes. Os discursos em torno desses trabalhadores são momentos de grande equivalência na arena política chinesa, sendo comuns 
frases de efeito, como "ajudem as empresas dos trabalhadores migrantes que retornarem para suas casas" ou "promovam o autoemprego entre os trabalhadores migrantes" (R11, 2-4).

A pretensão do discurso do guānxì é construir a hegemonia, diminuindo as diferenças existentes entre os diversos grupos com interesses estratégicos, construindo uma cadeia de equivalência, onde o interesse de um grupo aparece como sendo o interesse do conjunto das pessoas. A hegemonia constrói-se, também, por meio do antagonismo que deriva de sua exclusão da lógica da equivalência, embora as posições possam ser contraditórias e não antagônicas. De todo modo, fica evidente a necessidade de um discurso contrahegemônico, por meio do qual seja possível a articulação de um sistema capaz de tornar "as operações governamentais transparentes, de modo que não haja quaisquer oportunidades de procura de renda extra pelos funcionários do Estado, mesmo que em funções, demitidos ou aposentados. Só então os funcionários públicos corruptos perdem seu apelo para as corporações" (R3FP, 40-41).

\section{Lógica da diferença: relações de subordinação}

Na China, uma parcela significativa da população não se constitui como portadora de direitos por causa das (imensas) desigualdades sociais. Podemos dizer que são os sujeitos que não encontram acolhida nas cadeias equivalenciais que constituem os sentidos dos discursos do guānxì (p. ex., no nível governamental ou no campo dos negócios), que acaba por aprofundar essas desigualdades. Assim, as relações de subordinação podem se transformar em discursos das diferenças, uma vez que tematizam relações de poder historicamente fundadas e recriadas. A análise dos dados revela, por exemplo, que:

Guānxì é uma prática social e econômica generalizada em Shantou. Sun Guanghui, oficial superior do Partido em Shantou, disse que, agora, todo mundo em uma aldeia ou cidade vai ter que conduzir sua vida diária mais com a ajuda de guānxì que pela lei. Quando querem fazer algo, muitos não consideram em primeiro lugar se é legal ou não, mas eles vão primeiro pensar quem é a pessoa responsável que devem conhecer, ou quem pode ajudá-los a conhecer a pessoa responsável. (R2FP, 20-26).

Como resultado, esse discurso denota uma exclusão da parcela dos que não têm acesso a esse capital relacional, representando, assim, um obstáculo à criação de uma sociedade moderna baseada no Estado de Direito, como reza a ultrarracionalidade do mercado no mundo ocidental. Sob essa lógica, o guānxì é visto como uma forma cínica de relacionamento, ou um poder invisível que procura obter ganhos "pela porta dos fundos", colocando-se como uma alternativa à falta de base legal, ou às instituições econômicas "fracas".

Como esforço de apaziguamento da diversidade de relações antagônicas presentes no ambiente de negócios, em sua $17^{\mathrm{a}}$ Reunião ( $4^{\mathrm{a}}$ Seção), o Comité Central do próprio Partido Comunista Chinês reconheceu que o país precisa avançar na "formulação de políticas, na otimização de um serviço público eficiente e limpo, na transparência dos mecanismos financeiros e assim por diante [...]" (R10FP, 33-36). Além disso, considerouse que

[...] o ambiente de negócios do país carece de regras e códigos de conduta específicos para regulamentar o uso de conexões e determinaram que a prática de usar conexões para desafiar essas regras e códigos de conduta deve ser criminalizada. São necessárias mudanças nos conceitos tradicionais relacionados à corrupção nessa área em particular [...] (R10FP, 12-15).

Porém, por serem relações historicamente determinadas, as tentativas do discurso estatal de dar voz às reivindicações pelo direito à equivalência pode, nos termos de Laclau e Mouffe (2001), implicar um processo 
articulatório que pode criar uma ilusão de consenso pautada unicamente pela noção de racionalidade política, reduzindo as múltiplas formas de luta baseadas em valores morais definidos por grupos estratégicos.

Consequentemente, nas últimas duas décadas, criou-se na sociedade chinesa espaço para a construção de diferenças e de discursos que expressam os antagonismos entre os sujeitos das grandes e modernas cidades e os dos pequenos municípios em áreas remotas, de onde saem a maioria dos trabalhadores migrantes. Esses trabalhadores também enfrentam dificuldades em suas cidades de origem, pois, ao passarem longos períodos longe, quando retornam têm pouco ou nenhum guānxì ali, o que acaba dificultando o estabelecimento de articulações com vistas a constituir uma cadeia equivalencial que possibilite o acesso aos recursos. Nesse contexto, potencializa-se a emergência das diferenças.

Tais dificuldades são, também, comuns para os migrantes que desejam iniciar um empreendimento, como revela Li Yingui, um antigo trabalhador migrante que retornou à sua cidade natal para criar um negócio próprio. "Eu não tenho bens para hipotecar e não tenho guānxì (relações ou conexões) em nível governamental ou nos bancos. Eu já dei entrada em vários processos para empréstimos em instituições financeiras estatais, mas nunca tive resposta [...]" (R12PE, 13-18). Portanto, nada impede que, em situações de crise econômica, se construa um discurso anti-guānxì liderado, por exemplo, pelos trabalhadores migrantes.

A relação é antagônica quando a presença de um não deixa que o outro se constitua completamente. Essa relação guarda em si o paradoxo da possibilidade e da impossibilidade dos elementos antagônicos tomados entre si. Em outras palavras: considerando determinado sistema contraditório global, " $A$ só é $A$ porque nega $B ; B$ só é $B$ porque nega $A$; contudo, ambos somente são, uma vez que o outro se faz presente" (MENDONÇA, 2003b, p. 137).

Os resultados deste estudo remetem, ainda, a Laclau e Mouffe $(1985 ; 2001)$, quando afirmam que as identidades são formadas a partir de ordens discursivas que disputam sentido no campo da discursividade. Vale, neste ponto, lembrar que as condições de emergência são as que permitem que o discurso exista e faça sentido, em dado contexto. Desse modo, acreditamos que o que possibilitou a emergência do guānxì como discurso organizacional (fazendo com que se tornasse um discurso hegemônico) foi o fato de a China ter criado um sistema de desenvolvimento que privilegiou as grandes cidades (como Běijīng, Shànghăi e Guăngzhōu), em detrimento das cidades pequenas e localizadas em áreas remotas. Nessas grandes cidades, o padrão de vida é elevado, há melhores oportunidades de negócios e trabalho. No entanto, ali, a competitividade (sobretudo empresarial) é grande, representando um desafio para a maioria da população, que tem um nível de instrução muito baixo. É em um cenário como esse que o discurso do guānxì emerge e torna-se dominante, influente no campo organizacional, onde os recém-chegados encontram-se quase sempre fora das cadeias articulatórias que dão acesso aos agentes estratégicos. Considerando que não têm guānxì em suas cidades de acolhimento, isso "influencia tanto na busca de trabalho como em aquisições no setor público" (E1, 18-19).

\section{Equivalências e diferenças na constituição do guānxì}

Primeiramente, pela lógica que denuncia as diferenças a partir das demandas pela criminalização e reivindicação por um sistema mais inclusivo e democrático - semelhante às críticas que se faz no Brasil ao clientelismo e "jeitinho brasileiro" - atribuindo novos significados ao guānxì, isso constitui uma diversidade. O segundo modo, de legitimação do guānxì, dá-se ao entendê-lo como ativo organizacional, em que os relacionamentos pessoais e dinâmicos são utilizados para o exercício de influência e alcance de objetivos das organizações. Aqui, o guānxì estabelece sua equivalência com outros recursos, que, igualmente, precisam ser amealhados e acumulados, legitimando a exclusão das vozes discordantes, que negam a equivalência desse com outros recursos. 
Isso quer dizer que o guānxì, como discurso no campo dos relacionamentos sociais e das redes de negócios, está sempre sendo ameaçado em um jogo de significações. É, portanto, dinâmico, frágil e expõe, facilmente, sua condição provisória. Os discursos formam um conjunto bastante heterogêneo, no qual interesses de diversas entidades se entrecruzam, se opõem e se complementam em termos dos interesses que defendem, tendo em vista as posições que ocupam, em uma complexa movimentação no espaço social que envolve os negócios na China.

Além disso, o guānxì, como expressão micropolítica das relações negociais na China, surge como um aparato moral que preenche as lacunas existentes na engrenagem da economia de mercado chinesa que alia a prosperidade dos negócios e a incorporação das regras locais de relacionamento. Assim, não cabe, aqui, discutir a relevância de uma posição ou outra. Como afirma Pinheiro-Machado (2011), o importante é reconhecê-lo como um elemento constitutivo da complexa, particular e exclusiva cultura chinesa que é utilizado para a promoção de negócios e, como tal, não está isento de contradições e paradoxos.

Como elemento fundamental dos negócios, torna-se objeto de desejo dos empresários e governos na competição por lucros, cooptação de empregados e redução de tempo e entraves da burocracia. Nesse sentido, naturalmente vão emergir as visões conflitantes acerca dos negócios e das formas de conduzir e cumprir acordos entre os que acessam e os que não acessam os circuitos de dádivas e os elos afetivos, constituindo, de acordo com Pinheiro-Machado (2011, p. 124), um "mecanismo de inclusão, manutenção e exclusão de sujeitos e redes mercantis" em um processo que constitui uma elite econômica global que ruma a uma economia de mercado globalizada, mas que, ao mesmo tempo, mantém parcelas excluídas dessa arena.

\section{Conclusões, Recomendações e Implicações}

\section{Neste momento, retomamos à nossa pergunta de pesquisa: Como o guānxì tem sido apropriado enquanto discurso organizacional por empresas chinesas do setor terciário?}

O guānxì continua permeando o espírito do capitalismo chinês, situando-se no cerne da nebulosa interseção da ideologia estatal socialista com a economia de mercado, com persistência de laços e conexões pessoais no sistema econômico. Tem sido apropriado como discurso organizacional, para favorecer a criação e consolidação de interações sociais por meio do rénqíng (sentimento de obrigação e endividamento), sendo utilizado como forma de poder regulador alternativo do agir social que auxilia na redução de interferências burocráticas arbitrárias nos negócios.

Por ser uma prática discursiva e articulatória, pressupõe o estabelecimento de lógicas equivalenciais e a produção de diferenças, daí a opção pela análise discursiva inspirada em Laclau e Mouffe (1985; 2001).

Constatamos que o discurso do guānxì pode variar muito, dependendo da cadeia de equivalências associada a ele. Nesse sentido, pode universalizar seus conteúdos a ponto de ser impossível significá-lo de forma exata. Isso ocorre, segundo Laclau e Mouffe (1985; 2001), quando, em uma prática articulatória, a cadeia de equivalências expande polissemicamente seus conteúdos. A multiplicação das demandas sociais e a proliferação de antagonismos na China exigem formas cada vez mais políticas de reagrupamento social, tendo em vista a complexidade social na qual determinações econômicas, políticas, militares e tecnológicas concorrem para a determinação do movimento do todo. Em outras palavras, a heterogeneidade está na essência do guānxì, e suas próprias estabilizações parciais são hegemônicas por natureza.

A hegemonia das práticas discursivas do guānxì se constrói por meio das cadeias de equivalências, quando as diversas demandas se transformam em uma única luta. Assim, a partir das equivalências estabelecidas entre os participantes do grupo de relacionamentos, é possível articular as diferenças, de tal forma que elas diminuam seus significados particulares. No entanto, em um ambiente complexo, com disputas e tensões 
discursivas emergindo, nada impede que se construa um discurso da diferença, ou seja, anti-guānxì, liderado, por exemplo, pelos trabalhadores migrantes e setores mais liberais da sociedade chinesa.

Nesse sentido, dada sua heterogeneidade constitutiva, o guānxì demanda a existência de uma base de relacionamento "guānxìwang", que é uma identificação comum ou um passado compartilhado, ou seja, uma cadeia de equivalências, de acordo com Laclau e Mouffe (1985; 2001). Na inexistência dessa base, as organizações chinesas forjam a possibilidade de se inserirem nas cadeias hegemônicas na tentativa de criarem vínculos organizacionais ou realizarem negócios, por meio da identificação das fontes de influência (poder) no campo de atuação, como fazem os trabalhadores migrantes e recém-chegados em cidades, quando não têm guānxi.

Este estudo revela a necessidade de se entender melhor os elementos constituidores do guānxì, a considerar que seu foco nos vínculos de confiança de longo prazo o torna uma estratégia de cultivo de relacionamento ideal que deve ser adotado pelas organizações. Entretanto, novas pesquisas devem ser realizadas para explorar ainda mais esse fenômeno político como um processo contínuo, uma prática discursiva e articulatória em diversos contextos organizacionais, envolvendo, inclusive, organizações chinesas e estrangeiras.

Uma implicação gerencial deste estudo para as organizações ocidentais, mormente as brasileiras, é a necessidade de seus dirigentes entenderem que, nas transações comerciais com indivíduos e/ou organizações chinesas, estes irão inseri-los no contexto de suas próprias redes de relacionamento, uma vez que ele desempenha um papel importante na decisão relativa aos negócios, e isso pode exigir o cumprimento de obrigações com pessoas que não têm envolvimento direto no negócio em questão, além de demandar um tempo maior para a finalização desses negócios.

\section{Referências}

ALVESSON, M.; KÄRREMAN, D. Taking the linguistic turn in organizational research: challenges, responses and consequences. Journal of Applied Behavioral Science, v. 36, n. 2, p. 136-158, 2000a.

$\overline{53, \text { n. } 9}, \overline{\text { p. } 1125-1149,2000 \mathrm{~b} \text {. }}$. Varieties of

BARBOSA, L. O jeitinho brasileiro. 4. ed. Rio de Janeiro: Campus, 1992.

BERGER, P.; LUCKMANN, T. A construção social da realidade. 33. ed. Trad. Sousa Fernandes. Petrópolis, RJ: Vozes, 2011.

BURITY, J. A. Desconstrução, hegemonia e democracia: o pós-marxismo de Ernesto Laclau. 1997. Disponível em: <http://bibliotecavirtual.clacso.org.ar/ar/libros/brasil/nabuco/joan7.rtf>. Acesso em: 16 jan. 2013.

. Discurso, política e sujeito na teoria da hegemonia de Ernesto Laclau. In: MENDONÇA, D.; RODRIGUES, L.

P. (Orgs.). Pós-estruturalismo e teoria do discurso: em torno de Ernesto Laclau. Porto Alegre: EDIPUCRS, 2008. 35$51 \mathrm{p}$.

CHAN, K. B. (Org.). Chinese business networks. State, economy and culture. Singapore: Prentice Hall, 2000.

CHEE, H.; WEST, C. Myths about doing business in China. Nova York: Palgrave Macmillan, 2004.

CHEN, X. P.; CHEN, C. C. On the intricacies of the Chinese guānxi: a process model of guānxì development. Asia Pacific Journal of Management, v. 21, n. 3, p. 305-324, 2004. 
26, n. $1, \overline{\text { p. } 37-53}, 2009$.

Negative externalities of close guānxì within organizations. Asia Pacific Journal of Management, v.

CHUA, R. Y. J.; MORRIS, M. W.; INGRAM, P. Guānxì vs networking: distinctive configurations of affect- and cognition-based trust in the networks of Chinese vs American managers. Journal of International Business Studies, v. 40, n. 3, p. 490-508, 2009.

CHUNG, W. K.; HAMILTON, G. G. Social Logic as Business Logic: Guanxi, Trustworthiness, and the Embeddedness of Chinese Business Practices. In: APPELBAUM, R. P.; FELSTINER, W. L. F.; GESSNER, V. (Eds.). Rules and networks: The legal culture of global business. Oxford: Hart Publishing, v. 7, 2001. 325-347 p. (Oñati International Series in Law and Society).

CRESWELL, J. W. Projeto de pesquisa: métodos qualitativo, quantitativo e misto. 3. ed. Porto Alegre: Artmed, 2010.

DUNFEE T. W.; WARREN, D. E. Is Guanxi Ethical? A Normative Analysis of Doing Business in China. Journal of Business Ethics, v. 32, n. 3, p. 191-204, 2001.

FAIRHURTS, G. T.; PUTNAM, L. Organizations as discursive constructions. Communication Theory, v. 14, n. 1, p. 5-26, 2004.

FERNANDEZ, J. A. The gentleman's code of Confucius. Leadership by values. Organizational Dynamics, v. 33, n. 1, p. 21-31, 2004.

FOUCAULT, M. A arqueologia do saber. Rio de Janeiro: Forense Universitária, 1997.

GOLD, T. B. After comradeship: personal relations in China since the cultural revolution. The China Quarterly, v. 104 , p. $657-675,1985$.

.; GUTHRIE, D.; WANK, D. Social connections in China: institutions, culture, and the changing nature of guānxi. Cambridge: Cambridge University Press, 2004.

GRANT, D.; KEENOY, T.; OSWICK, C. Organizational discourse: of diversity, dichotomy and multi-disciplinarity. In: . (Ed.). Discourse and organization. Londres: Sage, 1998. 1-14 p.

. et al. Introduction: organizational discourse: exploring the field. In: . et al. (Eds.). Sage handbook of organizational discourse. Londres: Sage, 2004. 1-36 p.

GUTHRIE, D. Information Asymmetries and the Problem of Perception: The Significance of Structural Position in Assessing the Importance of Guanxi in China In: GOLD, T.; GUTHRIE, D; WANK, D. (Eds.). Social Connections in China: Institutions, Culture, and the Changing Nature of Guanxi. Cambridge, U.K.: Cambridge University Press, 2002. 37-56 p. (Structural Analysis in the Social Sciences).

HWANG, K. Face and Favor: The Chinese Power Game. American Journal of Sociology, v. 92, n. 4, p. 944-74, 1987.

JACOBS, J. B. A preliminary model of particularistic ties in Chinese political alliances: kan ch'ing and kuanhsi in a rural Taiwanese township. The China Quarterly, v. 78, p. 237-73, 1979.

KIPNIS, A. B. The Language of Gifts: Managing Guanxi in a North China Village. Modern China, v. 22, n. 3, p. 285314, 1996. Press, 1997.

Producing Guanxi: Sentiment, Self, and Subculture in a North China Village. Durham, NC: Duke University

LACLAU, E. Hegemony and socialist strategy: towards a radical democratic politics. 2. ed. Londres: Verso, 2001.

.; MOUFFE, C. Hegemony and socialist strategy: towards a radical democratic politics. Londres: Verso, 1985. 
LUO, Y. Guānxì and business. 2. ed. Hackensack, NJ: World Scientific, 2007.

MENDONÇA, D. A teoria do discurso de Laclau e Mouffe: em direção à noção de significante vazio. Barbarói, v. 18, p. 55-71, jan./jun. 2003a.

A noção de antagonismo na ciência política contemporânea: uma análise a partir da perspectiva da teoria do discurso. Revista de Sociologia e Política, n. 20, p. 135-145, 2003 b. $169,2009$.

Como olhar "o político" a partir da teoria do discurso. Revista Brasileira de Ciência Política, n. 1, p. 153-

.; RODRIGUES, L. P. (Orgs.). Pós-estruturalismo e teoria do discurso: em torno de Ernesto Laclau. Porto Alegre: EDIPUCRS, 2008.

MERRIAM, S. B. Qualitative research and case study applications in education. San Francisco: Jossey-Bass, 1998.

MILLER F. P.; VANDOME, A. F.; MCBREWSTER, J. Beijing Central Business District. Saarbrücken: VDM Verlag Dr. Mueller e.K., 2010.

MOTTA, F. C. P.; CALDAS, M. P. Cultura organizacional e cultura brasileira. São Paulo: Atlas, 1997.

MUMBY, D. K.; CLAIR, R. P. Organizational discourse. In: VAN DIJK, T. A. (Org.). Discourse as Social Interaction. London: Sage, 1997. 181-205 p.

OSWICK, C.; KEENOY, T. W.; GRANT, D. Discourse, organizations, and organizing concepts, objects and subjects. Human Relations, v. 53, n. 9, p. 1115-1124, 2000.

PARK, S. H.; LUO, Y. Guānxì and organizational dynamics: organizational networking in Chinese firms. Strategic Management Journal, v. 22, n. 5, p. 455-477, 2001.

PEREIRA, T. V. Tradição e inovação: sentidos de currículo que se hibridizam nos discursos sobre o ensino de Ciências nos anos iniciais do Ensino Fundamental. 2011. 193 f. Tese (Doutorado em Educação) Faculdade de Educação, Universidade do Estado do Rio de Janeiro, Rio de Janeiro, 2011.

PESSOA, C. Hegemonia em tempos de globalização. In: MENDONÇA, D.; RODRIGUES, L. P. Pós-estruturalismo e teoria do discurso: em torno de Ernesto Laclau. Porto Alegre: EDIPUCRS, 2008. 133-144 p.

PHILLIPS, N.; HARDY, C. Discourse analysis: investigating processes of social construction. Newbury Park, CA: Sage, 2002.

PINHEIRO-MACHADO, R. Fazendo guānxì: dádivas, etiquetas e emoções na economia da China pós-Mao. Mana, v. 17, n. 1, p. 99-130, 2011.

PINTO, C. R. J. Elementos para uma análise de discurso político. Barbarói, v. 24, p. 87-118, 2006.

PUTNAM, L. L.; FAIRHURST, G. T. Discourse analysis in organizations. In: JABLIN, F. M.; PUTNAM, L. L. (Eds.). The new handbook of organizational communication. Thousand Oaks, CA: Sage 2001. 78-136 p.

SHI, G. et al. The role of rénqíng in mediating customer relationship investment and relationship commitment in China. Industrial Marketing Management, v. 40, n. 4, p. 496-502, 2011.

SMART, A. Gifts, bribes and guānxì: a reconsideration of Bourdieu's social capital. Cultural Anthropology, v. 8, n. 3, p. 388-408, 1993.

TIAN, X. Managing international business in China. Cambridge: Cambridge University Press, 2007. 
VERGARA, S. Métodos de pesquisa em administração. 4. ed. São Paulo: Atlas, 2010.

VERHEZEN, P. Gift and alliances in Java. Ethical Perspectives, v. 9, n. 1, p. 56-65, 2002. 2003.

. From a culture of gift exchange to a culture of exchanging gifts. Jurnal Antropologi, v. 27, n. 72, p. 101-115,

. Guānxì: networks or nepotism? The dark side of business networks. In: ZSOLNAI, L. Europe-Asia dialogue on business spirituality. Antuérpia: Garant, 2008. 89-106 p.

WANG, C. L. Guānxì vs. relationship marketing: exploring underlying differences. Industrial Marketing Management, v. 36, n. 1, p. 81-86, 2007.

YAN, Y. The Culture of Guanxi in a North China Village. The China Journal, n. 35, p. 1-25, 1996.

YANG, M. M. Gifts, favors, banquets: the art of social relationship in China. Ithaca, NY: Cornell University Press, 1994.

. The resilience of guānxì and its new deployments: a critique of some new guānxì scholarship. China Quarterly, v. 170, p. 459-476, 2002.

YEUNG, I. Y. M.; TUNG, R. L. Achieving business success in Confucian societies: the importance of guānxì (connections). Organizational Dynamics, v. 25, n. 2, p. 54-65, 1996.

YUMEI, H. The Stakeholder View with Guanxi: A Case Study of Managers in Chinese Aquatic Product Industry. 2009. 86 p. Dissertação (Mestrado em Pesca, gestão e economia da aquacultura). The Norwegian College of Fishery Science University of Tromso/Nha Trang University, Norway, 2009

WANK, D. L. The Institutional Process of Market Clientelism: Guanxi and Private Business in a South China City. The China Quarterly, v. 144, p. 820-838, 1996. 